\title{
Nutritional status of adolescent girls in a rural area of Bangladesh: A cross sectional study
}

\author{
A. Begum*, K. N. Sharmin, M. A. Hossain, N. Yeasmin and T. Ahmed \\ Department of Applied Food Science and Nutrition, Chittagong Veterinary and Animal Sciences University (CVASU), \\ Chittagong-4225, Bangladesh
}

\begin{abstract}
The improvement of adolescent nutritional status may help address the reduction of all forms of malnutrition in Bangladesh. This is because at this stage, they experience a growth spurt thus increasing the need for most nutrients, needed for growth and reproductive health. The objective of this research was to assess the nutritional status of adolescent girls in rural areas of Bangladesh and find out the associated factors that affects nutritional status. A cross sectional study was carried out among 106 adolescent girls of Nobabpur village in Comilla district. A questionnaire was developed to obtain demographic information, food intake pattern and anthropometric measures such as weight, height with measuring instruments. About $80 \%$ were found normal according to BMI where about $13 \%$ adolescent girls were malnourished, below the cut off value 18.5. Place of residence, education of adolescent girls, their family expenditure to food and improper knowledge on food and nutrition were identified as underlying causes. Nutritional profiles of adolescent girl can be improved by implementing effective nutrition education program, providing supplementary food, facilitating primary health care program and creating awareness about nutritional knowledge. Severely malnourished adolescent girl in the selected area should be identified as early as possible and brought under supplementary feeding program.
\end{abstract}

Key Words: Adolescent girl; Nutritional status; Body mass index (BMI)

\section{Introduction}

Nutritional status is defined as the condition of the body in those respects influenced by the diet; the levels of nutrients in human body and the ability of those levels to maintain normal metabolic integrity (Saxena and Saxena, 2009). Essential nutrient must be provided to body by the diet otherwise its inadequate causes health problems such as malnutrition. According to WHO (2006) adolescence as the period in human growth and development that occurs after childhood and before adulthood, from ages 10 to19. Biological processes drive many aspects of this growth and development, with the onset of puberty marking the passage from childhood to adolescence (Mulugeta et al., 2009) Growth during adolescence is faster than at any other time in an individual's life except the first year. Good nutrition during adolescence is critical to cover the deficits suffered during childhood and should include nutrients required to meet the demands of physical and cognitive growth and development, provide adequate stores of energy for illnesses and pregnancy and prevent adult onset of nutrition-related diseases (WHO, 2006).
Like other South-Asian countries, Bangladesh has shown deficiencies in the intake of all nutrients, particularly iron, calcium, vitamin $\mathrm{A}$ and vitamin $\mathrm{C}$. The main reasons are mainly the low educational level of parents and low family income. Dietary intake with respect to adequate availability of food in terms of quantity and quality (particularly, the mean caloric intake), ability to digest, absorb and utilize food and the social discriminations against girls can greatly affect the adequate nutrition of adolescents. Many boys and girls enter adolescence undernourished, making them more vulnerable to disease and early death. Conversely, overweight and obesity another form of malnutrition with serious health consequences is increasing among other young people in both low and high income countries (Cole et al., 2007).

Adequate nutrition and healthy eating and physical exercise habits at this age are foundations for good health in adulthood. Adolescents are the best human resources. But for many years, their health has been neglected because they were considered to be less vulnerable to disease than the young children or the very old. Their

*Corresponding author e-mail: asha03du@gmail.com 
health attracted global attention in the last decade only. As adolescents have a low prevalence of infection compared to under-five children, and of chronic disease compared to ageing people, they have generally been given little health and nutrition attention, except for reproductive health concerns (Kalhan et al., 2010). Malnourished adolescent girls who have babies at a young age are likely to experience, and will be less able to withstand, complications because the body has not yet reached maturity. Maternal mortality is higher in anemic women. Even when they survive, poorly nourished adolescent mothers are more likely to give birth to low birth-weight babies, perpetuating a cycle of health problems which pass from one generation to the next (Kumar, 2012). Hence it is essential to assess the nutritional status of adolescence girls, especially developing countries like Bangladesh. The objective of the present work is to assess the nutritional status of adolescent girls in rural areas of Bangladesh and find out the associated factor that affects nutritional status.

\section{Materials and methods}

\section{Subjects and study area}

To assess, analyze and evaluate the lifestyle; health and nutritional profile of adolescent girls various types of anthropometric, socio economic, food intake pattern and knowledge about nutrition have been collected from adolescent girls of the target population. For this purpose 106 adolescent girls were selected randomly for this study. The study was carried out at Nobabpur of Comilla, to find out the lifestyle, health and nutritional status of adolescent girls of that area.

\section{Study design}

The study was cross sectional in nature. The data were collected at one point of time from samples selected to describe the situation of nutritional status of adolescent girls.

\section{Collection of demographic data}

A Questionnaire was developed to obtain relevant information on age, sex, weight, socio-economic history through interview of the adolescent girls. A structured interview where asked to know the food intake pattern among adolescent girls.

\section{Anthropometric data}

To assess the nutritional status, the anthropometric measures such as weight, height and BMI were taken. A lever balance (Detecto-Medic, Detecto scales, USA) was used to record body weight (Anand et al., 1999). Body weight recorded to the nearest $0.5 \mathrm{Kg}$ on bare foot with minimum clothing. Height of the subjects were measured with a standard scale to the nearest $1 \mathrm{~cm}$ in standing up-straight without assistance, with bared heels close together. Legs straight, arms at the sides and shoulders relaxed, looking straight ahead. During measurement of height the person was allowed to take asleep breath and at maximum inspiration was recorded.

\section{Calculation of Body mass index (BMI)}

Body Mass Index (BMI) is an anthropometric index of weight and height that is defined as body weight in kilograms divided by height in meters squared. BMI of adolescent girls were calculated by using the following equation:

Body mass index $(\mathrm{BMI})=$ Weight in kilogram $(\mathrm{kg}) /$ Height in $\operatorname{meter}^{2}\left(\mathrm{~m}^{2}\right)$

BMI is the commonly accepted index for classifying adiposity in adults and it is recommended for use with children and adolescents (Ulijaszek and Kerr, 1999).

\section{Statistical analysis}

The obtained data were stored in Microsoft Excel 2007 and then exported into SPSS Version 17.0 software (SPSS Inc., USA) for statistical analysis. Data of anthropometric and food habit pattern were analyzed by following above statistical procedure to assess the nutritional status of the children.

\section{Results and discussion}

A cross sectional study was carried out among the households with adolescent girls who were selectively selected in a village named Nobabpur. The educational status of adolescent girls is presented in Table-I.

Figure-1 shows the percent expenditure pattern of studied household. It reflects that only $2.76 \%$ cost is for housing, $14.95 \%$ expense is made for education, medicine and clothing costs almost equally but food is the largest sector of expenditure $(53.73 \%)$. 
Table I. Education level of adolescent girls

\begin{tabular}{lcc}
\hline Class & Frequency & Percent \\
\hline Class1-Class5 & 36 & 33.9 \\
Class6-Class10 & 50 & 47.2 \\
HSC to higher & 13 & 12.3 \\
Illiterate & 1 & 0.9 \\
Can sign & 3 & 2.8 \\
Can read and write & 3 & 2.8 \\
Total & 106 & 100 \\
\hline
\end{tabular}

do not familiar with iodine rich food but $86.8 \%$ family used iodized salt.

Figure-2 shows BMI, formerly called the Quetelet index, is a measure for indicating nutritional status in adolescent girls. Most of the adolescent girls about $80 \%$ were normal in range and $13 \%$ were malnourished in total.

With greater emphasis on the health of the women in general and the girl child in particular, the picture of nutritional status seen in the rural girls of Bangladesh is alarming though not surprising (Vasanthi et al., 1994). The poor nutritional status of adolescents, especially girls, has important implications in terms of physical work capacity and adverse

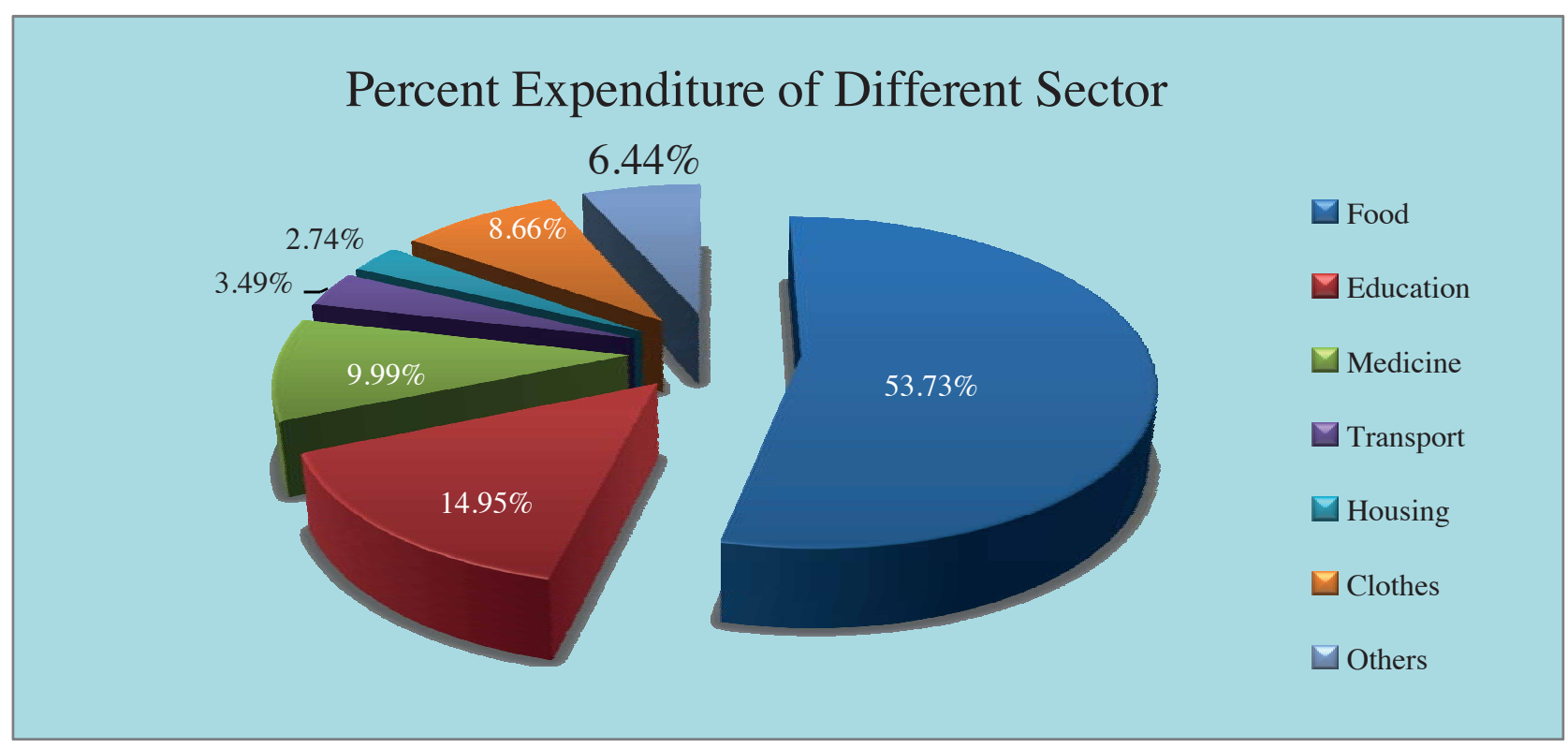

Fig. 1. Expenditure pattern of studied household

Table-II shows the adolescent girl's nutrition knowledge such as sufficiency of the vegetables taken, habit of taking vitamin $\mathrm{C}$ rich foods, concept about iron rich foods, eating iron rich foods, knowledge about iron deficiency, knowledge about the occurrences of symptoms due to iron deficiency, sufferings experienced from the occurrences of vitamin A deficiency diseases, having the symptoms of vitamin $\mathrm{C}$ deficiency disease, knowledge about anemia and experienced sufferings from anemia.

In Table-III, it shows that, $66.9 \%$ household have no idea about balance diet .Imbalance intake of food would lead to deficit/excess of nutrient intake $66.9 \%$ of households ,who have no idea about balance diet. Although $56.6 \%$ households reproductive outcomes (Haboubi and Shaikh, 2009). Adolescents (aged 10 to 19 years) have specific health and development needs, and many face challenges that hinder their wellbeing. It has been reflected in various studies and surveys done over 1991 to 2000 by different national and international bodies that nutrition and health situation particularly women, children and adolescent girls is grave in this country (WHO, 2006).

The main cause of poor nutritional status is the lack of knowledge of nutrition among the girls. Although significant rate of illiteracy does not prevail but $33.9 \%$ girl has dropped from primary school where $47.2 \%$ has entered higher study. 


\section{Table II. Knowledge about nutrition}

\begin{tabular}{|c|c|c|}
\hline Variables & Frequency & Percentage \\
\hline Sufficient & 62 & 58.5 \\
\hline Don't getting enough & 44 & 41.5 \\
\hline Total & 106 & 100 \\
\hline \multicolumn{3}{|c|}{ Habit of taking Vitamin $\mathrm{C}$ rich foods $(\mathrm{n}=106)$} \\
\hline Intake regularly & 83 & 78.3 \\
\hline Irregular intake & 23 & 21.7 \\
\hline Total & 106 & 100 \\
\hline \multicolumn{3}{|l|}{ Concept about Iron rich foods $(\mathrm{n}=106)$} \\
\hline Potatoes & 10 & 9.4 \\
\hline Fish/meat & 22 & 20.8 \\
\hline Pulse & 15 & 14.1 \\
\hline Vegetables & 40 & 37.7 \\
\hline Others & 19 & 17.9 \\
\hline Total & 106 & 100 \\
\hline \multicolumn{3}{|c|}{ Eating of the above mentioned iron rich foods $(n=106)$} \\
\hline Intake & 89 & 83.9 \\
\hline Devoid of in taking iron rich foods & 17 & 7.7 \\
\hline Total & 106 & 100 \\
\hline \multicolumn{3}{|c|}{ Knowledge about iron deficiency $(n=106)$} \\
\hline Concerned about IDD & 42 & 39.6 \\
\hline Not concerned about IDD & 64 & 60.4 \\
\hline Total & 106 & 100 \\
\hline \multicolumn{3}{|c|}{ Knowledge about the occurrences of symptoms due to iron deficiency $(n=106)$} \\
\hline Nausea & 10 & 9.4 \\
\hline Vomiting & 24 & 22.6 \\
\hline Colorless of tongue, lip, nail & 1 & 0.9 \\
\hline Infection of tongue and lip & 9 & 8.5 \\
\hline Fragile nail & 10 & 9.4 \\
\hline Headache & 13 & 12.3 \\
\hline Depressed & 7 & 6.6 \\
\hline Others & 32 & 30.1 \\
\hline Total & 106 & 100 \\
\hline \multicolumn{3}{|c|}{ Sufferings from the occurrences of vitamin A deficiency diseases $(n=106)$} \\
\hline Night blindness & 1 & 0.9 \\
\hline Bitot's spot & 1 & 0.9 \\
\hline Dryness of skin & 39 & 36.8 \\
\hline Not occurred & 65 & 61.32 \\
\hline Total & 106 & 100 \\
\hline
\end{tabular}


Having the symptoms of vitamin C deficiency disease $(n=106)$

Blood release from the root of the teeth

$30 \quad 28.3$

Soreness of the root of the teeth

7

6.6

Absence of symptoms

Deserve no knowledge about Vit-C deficiency problem

Total 106

Knowledge about anemia(n=106)

Have heard about

No clear idea

Total

106

100

Table III. Perception of adolescent girls about balance diet and different common disease related to nutrition

Parameter Prequency Pentage

Knowledge about balanced $\operatorname{diet}(\mathrm{n}=106)$

Have heard about

$35 \quad 33.0$

Have no idea

Total

Knowledge about Goiter protecting foods $(n=106)$

Iodized salt, vegetables \& fruits, marine fish

Poor concept

Not conscious

Total

Usage of iodized salt $(\mathrm{n}=106)$

Taking iodized salt

Take non iodized salt

Total

Protein rich Body building foods $(n=106)$

Rice

Fish

Vegetables

Not concerned about body building \& repair

Total

Knowledge about protective foods $(\mathrm{n}=106)$

Vegetables \& fruits

Egg, milk

Fish, meat

Unfamiliar with the protective action of food

Total

Knowledge about Vitamin A rich foods $(\mathrm{n}=106)$

Vegetable

Dal

Milk

Rice

Not concerned about dietary intake of vitamin-A 


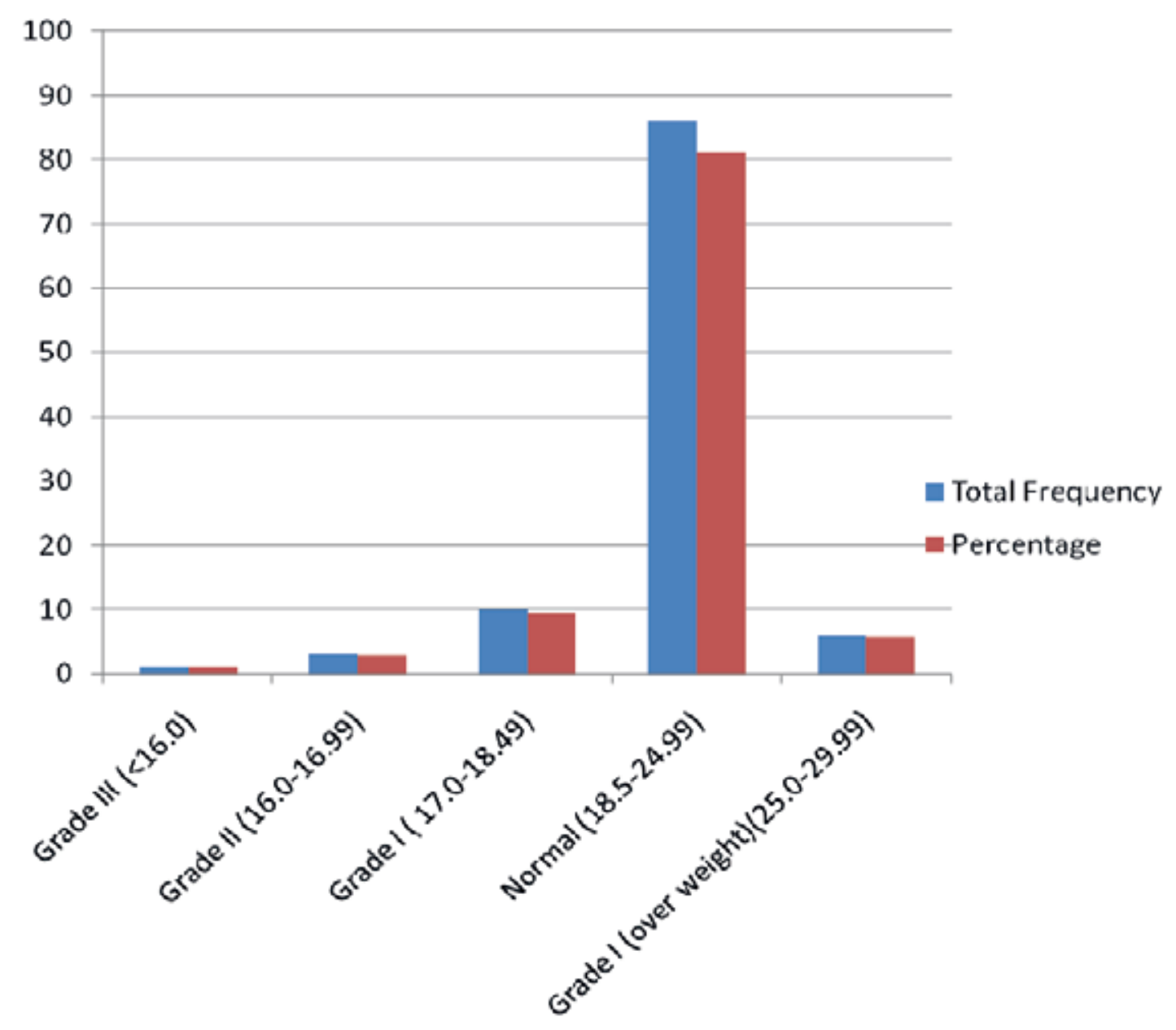

Fig. 2. Nutritional status of adolescent girls based on BMI (body mass index)

Attaining a degree from university or college was very rare among adolescent girl only $12.3 \%$. Level of education has a significant independent effect on nutritional status in adolescent girls. Present study showed that, a tendency towards an increase nutritional status in adolescent girls with an increase in the level of their education. This may due to the relatively better understanding of public health knowledge to improve the nutritional status of adolescent girls (Mulugeta et al., 2009).

Another cause is the expenditure pattern of studied household where these adolescent girls belong. Household cost for food was vast and largest share among other basic needs and it is $53.73 \%$ of total expenditure. This is one of the factors which affect the nutritional status of adolescent girls. They also bought cloth costing 9\% percent of their total expenditure. Treatment and curing of disease was expensed with $10 \%$ of expenditure. Present study observed that a tendency towards an increase nutritional status in adolescent girls with an increase in the family cost for food.

Adolescent girl nutrition knowledge and experienced sufferings can be explained as $58.5 \%$ adolescent girls took sufficient vegetable and almost $78.3 \%$ took citrus foods regularly. Vegetables are good source of iron according to $37.7 \%$ adolescent girl. Significant proportion of adolescent girl was 
not concern about iron deficiency anaemia (IDA), vitamin A deficiency disorders, iodine deficiency disorders, and vitamin $\mathrm{C}$ deficiency disorder. $61.3 \%$ adolescent girl did not know about anemia and unable to confirm their position in at risky group of IDA along which among them $51.8 \%$ have experienced anemic condition in variably with different symptoms. Adolescent girls who have relatively better understanding of the public health and nutritional knowledge yield improve pattern of nutritional status.

Most of adolescent girls about $80 \%$ exist in normal range whereas only $13 \%$ were malnourished. Research has shown that better-nourished girls have higher pre-menarche growth velocities and reach menarche earlier than undernourished girls, who grow more slowly but for a longer, as menarche is delayed (WHO, 2006). Because underweight girls are growing for longer duration, they may not finish growing before their first pregnancy. Adolescents with a BMI above the 25-29.99 are at risk for overweight. Weight gain is the result of a positive energy balance (consuming more energy than is expended). Energy expenditure, as assessed through levels of physical activity, declines in children as they reach adolescence, particularly in adolescent girls (Naidu and Rao,1994).There is evidence that children and adolescents of rural families are more overweight than in the past, possibly because of decreased physical activities, sedentary lifestyle, altered eating patterns and increased fat content of the diet. Increase in sedentary activities, such as television viewing and computer games, is suspected to be responsible for the decline in physical activity levels (WHO, 2006).

That adolescent girls have no access to resource and power, improper personal hygiene practices, poor knowledge about food and health, lower income of the family, high prevalence of stunting, wasting, underweight and thinness, and vulnerable to domestic abuse and violence is not unknown to third world country like Bangladesh. It should be emphasized to improve their situation without any subterfuge through preserving their right, proper health and care, necessary preventives and curatives, enriched balanced diet and ensuring sustainable environmental heath, which demand paramount allocation of resource towards adolescent development to have a glorious future for all.

\section{Conclusion}

The present study reveals that nutritional status of adolescent girl in rural area of Bangladesh is in satisfactory level with minimal malnourished adolescent girl. Nutritional deprivation affects almost all growth parameters and final adult body size resulting in thinness and stunting. However, nutritional status of both boys and girls improved with age, showing that the effect of malnutrition is more pronounced at the time of peak growth. Nutritional profiles of adolescent girl can be improved by implementing effective nutrition education program, providing supplementary food, facilitates primary health care program and creating awareness about nutritional knowledge. The least number of severely malnourished adolescent girls in the selected area should be identified as early as possible and brought under supplementary feeding program for improvement of their health status.

\section{Acknowledgement}

We are thankful to authors of this research for the technical support.

\section{References}

Anand K, Kant S and Kapoor SK (1999), Nutritional status of adolescent school children in rural north India, Indian pediatrics 36: 810-816.

Cole TJ, Flegal KM, Nicholls D and Jackson AA (2007), Body mass index cut offs to define thinness in children and adolescents: international survey, British Medical Journal 335(7612): 194.

Haboubi GJ and Shaikh RB (2009), A comparison of the nutritional status of adolescents from selected schools of South India and UAE: a cross-sectional study, Indian journal of community medicine: official publication of Indian Association of Preventive \& Social Medicine 34(2): 108.

Kalhan M, Vashisht B, Kumar V and Sharma S (2010), Nutritional status of adolescent girls of rural Haryana. The Internet Journal of Epidemiology 8(1).

Kumar A (2012), Nutritional status of adolescent girls in rural Tamilnadu Religion, National Journal of Medical Research 1(1): 48-51.

Mulugeta A, Hagos F, Stoecker B, Kruseman G, Linderhof V, Abraha Z, Yohannes M and Samuel GG (2009), Nutritional status of adolescent girls from rural communities of Tigray, Northern Ethiopia. Ethiopian Journal of Health Development 23(1).

Naidu AN and Rao NP (1994), Body mass index: a measure of the nutritional status in Indian populations, European Journal of Clinical Nutrition 48: S131-40. 
Saxena Y and Saxena V (2009), Nutritional status in rural adolescent girls residing at hills of Garhwal in India (2011), Internet Journal of Medical Update-EJOURNAL 6(2).

Ulijaszek SJ and Kerr DA (1999), Anthropometric measurement error and the assessment of nutritional status, British Journal of Nutrition 82(03): 165-177.

Vasanthi G, Fawashe AB, Susie H, Sujatha T and Raman L (1994), Iron nutritional status of adolescent girls from rural area and urban slum, Indian Pediatrics 31: 127-132.
WHO, World Health Organization (2006), Adolescent nutrition: a review of the situation in selected South-East Asian countries. SEA/NUT/163, New Delhi, Regional Office for South East Asia.

Received: 05 January 2017; Revised: 31 January 2017; Accepted: 29 May 2017. 